УДК 101

$10.17213 / 2075-2067-2020-6-264-274$

\title{
СОВРЕМЕННОЕ РОССИЙСКОЕ НЕОЯЗЫЧЕСТВО: ОПРЕДЕЛЕНИЕ, КЛАССИФИКАЦИЯ, ОСНОВНЫЕ ТЕЧЕНИЯ
}

\author{
(ㄷ) 2020 г. И. А. Левандина , И. В. Липчанская ${ }^{* *}$ С. И. Самыгин** \\ "Ростовский юридический институт МВД России, г. Ростов-на-Дону, Россия \\ "Ростовский государственный экономический университет (РИНХ), \\ 2. Ростов-на-Дону, Россия
}

Цель исследования. Целью статьи является анализ современного положения российского неоязычества, а также основных теоретических и методологических проблем, возникающих при исследовании этого феномена. При этом особое внимание уделяется так называемому «славянскому неоязычеству».

Методология исследования базируется на сравнительно-аналитическом подходе к исследованию феномена неоязычества.

Результаты исследования. $B$ статье показано, что современное отечественное неоязыческое движение представляет собой чрезвычайно пестрый по своему составу, идеологическим и вероучительным установкам феномен, что создает значительныле теоретические и методологические трудности при его комплексном изучении.

Перспективы использования результатов исследования. Результаты исследования могут быть использованы в ходе дальнейших изучений феномена неоязычества, разработке учебных курсов для высшей школы, а также при принятии управленческих решений в сфере государственно-конфессиональных отношений.

Ключевые слова: неоязычество; родноверие; инглиизм; викка; новые религиозные движения.

\section{MODERN RUSSIAN NEO-PAGANISM: DEFINITION, CLASSIFICATION, MAIN TRENDS}

\section{(C) 2020 I. A. Levandina*, I. V. Lipchanskaya ${ }^{* *}$ S. I. Samygin ${ }^{* *}$}

\section{"Rostov Law Institute of the Ministry of Internal Affairs of Russia, Rostov-on-Don, Russia \\ ${ }^{* *}$ Rostov State University of Economics (RSUE), Rostov-on-Don, Russia}

Purpose of the study. The purpose of the article is to analyze the current state of Russian neo-paganism, as well as the main theoretical and methodological problems that arise in the study of this phenomenon. At the same time, special attention is paid to the so-called "Slavic neopaganism».

The research methodology is based on a comparative-analytical approach to the study of the phenomenon of neo-paganism.

Research results. The article shows that the modern domestic neo-pagan movement is an extremely variegated phenomenon in its composition, ideological and doctrinal attitudes, which creates significant theoretical and methodological difficulties in its comprehensive study.

Prospects for using the research results. The results of the study can be used in the course of further research on the phenomenon of neo-paganism, in the development of training 
courses for higher education, as well as in making managerial decisions in the field of stateconfessional relations.

Key words: neo-paganism; rodnoverie; ingliism; wicca; new religious movements.

Введение. Неоязыческое движение, бурно распространяющееся в последние годы по всему миру, в том числе и в нашей стране, уже довольно давно привлекает внимание исследователей. Особо пристально отечественные специалисты, как и следовало ожидать, анализируют российское неоязычество. К настоящему времени существует значительный объем научных публикаций, рассматривающих различные аспекты этого явления [1, $2,3]$. Однако, несмотря на впечатляющий объем проделанной работы, многие аспекты этой проблематики до сих пор остаются дискуссионными. Так, и по сей день предметом научных споров являются само определение понятия «неоязычество», используемая терминология, классификация неоязыческих групп и объединений. В предлагаемой статье проводится обсуждение и анализ обозначенных проблем, а также краткий обзор современного состояния российского неоязычества. Мы также уделим внимание проблемам, связанным с теми угрозами общественной безопасности, которые создают отдельные неоязыческие группировки.

Определение и терминология. Прежде всего, нам необходимо определить понятие «неоязычество» или «неоязыческое движение». Мы будем понимать под неоязычеством реконструкции (точнее, попытки реконструкции) политеистических верований, существовавших до принятия авраамических монотеистических религий. Специально оговоримся: хотя в абсолютном большинстве случаев речь идет о реконструкции дохристианских верований европейских народов, мы все же считаем необходимым расширить определение, включив в него, помимо христианства, также иудаизм и ислам. Мы делаем это потому, что в современном мире существуют неоязыческие объединения, ставящие перед собой именно такую программу возвращение к доисламским и доиудейским религиозным представлениям. Например, к таковым относятся неотенгрианство, по- лучившее некоторое распространение среди представителей тюркских мусульманских народов, в основном в Центральной Азии, а также среди башкир и татар, и движение израэлитов, представленное по большей части среди евреев Израиля.

Далее нам необходимо определиться и с терминологией, то есть уточнить, что конкретно мы будем подразумевать под «неоязычеством» вообще и «славянским неоязычеством» в частности. Это сделать необходимо, так как консенсус по этому вопросу в отечественной литературе еще не сложился, более того, некоторые авторы ставят под вопрос саму правомерность использования термина «неоязычество», поэтому вначале было бы уместно обсудить именно вопрос о правомерности терминологии.

По нашему мнению, такой термин, как «неоязычество», имеет полное право на использование в научной литературе. Возражения против использования этого термина, насколько можно судить, сводятся в целом к утверждению, что он воспринимается как оскорбительный самими последователями неоязыческих учений. Следовательно, как утверждают противники его использования, он не может присутствовать в научной литературе, которая должна пользоваться нейтральным языком. Однако мы полагаем, что это обстоятельство вряд ли может служить решающим аргументом в определении дальнейшей судьбы данного термина в научном языке. Здесь надо прежде всего принять во внимание причину, по которой сами последователи неоязычества выступают против того, чтобы их называли неоязычниками. Дело в том, что неоязычники против этого термина не потому, что он имеет какое-либо оскорбительное или уничижительное значение в обиходном языке, как, например, термин «секта» (но даже и в случае с последним мы не считаем это достаточной причиной для пересмотра научной терминологии).

Возражения, выдвигаемые неоязычниками, имеют идеологический и мировоззрен- 
ческий характер. Конкретно: неоязыческие группы считают себя наследниками и носителями дохристианской традиции, которая будто бы существует непрерывно с древних времен и до наших дней. Следовательно, приставка «нео», по их убеждению, равнозначна отрицанию их вероучения и, значит, делигимитизации их доктрин. На последнее обстоятельство стоит обратить особое внимание. В последние годы многие неоязыческие объединения прикладывают немалые усилия для того, чтобы получить и официальное признание в качестве зарегистрированных «традиционных» религиозных объединений, и признание со стороны широких слоев общества. Основным аргументом здесь как раз и служат указания на собственную «аутентичность», что, разумеется, невозможно сделать, не принимая допущения о существовании непрерывной традиции. Кроме того, отечественные неоязыческие группы стремятся заручиться если не поддержкой, то хотя бы благожелательным нейтралитетом со стороны существующих в нашей стране организаций, представляющих религии народов, действительно сохранивших в непрерывной передаче дохристианские религиозные верования. К числу таковых относятся, например, марийцы или народы крайнего Севера. В последние годы отечественные неоязыческие организации, как мы могли наблюдать, созывали конференции, громко обозначавшиеся как конференции последователей традиционных религий, к участию в которых приглашались наряду с неоязычниками и представители традиционных марийских или шаманистских религиозных объединений.

Однако же, и в этом сходятся все без исключения академические исследователи религий, претензии неоязычников на наличие непрерывной религиозной преемственности полностью лишены каких-либо оснований. Нет ни единого заслуживающего доверия документального подтверждения существования непрерывной передачи религиозных верований с дохристианских времен и до наших дней. Более того, даже попытки реконструкции дохристианских верований населявших нашу страну славянских племен сталкиваются с неразрешимыми трудностями. Таким образом, любая попытка практиковать дохристианские религиозные цере- монии, жертвоприношения, любые другие культовые действия предполагает изрядный элемент фантазии, воображения, религиозного творчества. Аналогично обстоит дело и со славянской мифологией, и с пантеоном богов: ни один миф не сохранился до наших дней, и о славянском пантеоне наука имеет в целом достаточно смутные и обрывочные представления. Но без сколько-нибудь тщательной проработки мифологии и ритуала никакая полноценная жизнь религиозной общины не возможна $[4,5]$.

Обобщая сказанное, мы с неизбежностью приходим к следующему выводу: отказ академического исследователя от термина «неоязычество» отнюдь не будет свидетельствовать об академическом нейтралитете. Наоборот, исследователь в таком случае даже против своего желания займет вполне определенную позицию. И эта позиция будет ничем иным, как проявлением солидарности с необоснованными претензиями адептов неоязычества на аутентичность и, более того, санкционированием и «освящением» этих притязаний своим научным авторитетом.

Подводя итог нашему обсуждению правомерности использования термина «неоязычество», сформулируем вывод: нет никаких разумных оснований отказываться от этого термина, который, несмотря на все дискуссии, является все же наиболее распространенным в научной среде. Мы полностью согласны в этом вопросе с таким видным исследователем современного российского неоязычества, как В.А. Шнирельман, и многими другими авторами. Добавим, что В.А. Шнирельман отмечает и такой существенный момент, характерный для неоязыческих попыток реконструкции: все современные неоязычники - городские жители, весьма далекие от мировоззрения и образа жизни древних земледельцев, которым они пытаются подражать: «Речь идет об общенациональной религии, искусственно создаваемой городской интеллигенцией из фрагментов древних дохристианских локальных верований и обрядов с целью “возрождения национальной духовности"» [6, с. 37]. И заметим от себя по этому поводу, что неоязыческие общины, как правило, сосредоточены в крупных городах - столицах или административных центрах. 
Попробуем теперь определить границы такого явления, как неоязычество. Здесь мы тоже можем констатировать отсутствие единого исследовательского подхода (хотя разногласий здесь в целом меньше, чем в первом случае). Основная «линия водораздела» проходит, как нам представляется, между конфессиональными (конкретно - христианскими) и светскими авторами, причем первые зачастую склонны понимать неоязычество весьма широко, относя к неоязыческим и неоиндуистские группы, и группы движения «нью эйдж», и другие [7].

Такой подход христианских авторов вполне объясним: в самом деле, в христианской традиции принято называть «язычниками» последователей всех неавраамических религий. Соответственно, последователи неоиндуизма, необуддизма и т.д. вполне могут именоваться при таком подходе «неоязычниками». Убедительность этой позиции придает тот факт, что сам термин «неоязычество», как производный от «язычества», восходит в конечном счете к христианской традиции, так как «язычество» - христианский по своему происхождению термин. Однако в этом случае, как мы считаем, происходит неоправданное расширение охвата, так как в число неоязыческих попадают практически все новые религиозные движения, за исключением имеющих библейское происхождение. Это существенно снижает эвристические возможности, так как не позволяет выделить специфику различных групп неорелигиозных образований, и в частности, тех, которые по уже сложившейся традиции именуются неоязычниками, если так можно сказать, «в узком смысле». Возможно, такой расширенный охват необходим для конфессиональной публицистики, для апологетических целей (здесь мы не считаем себя вправе выносить какие-либо суждения), но в светской науке это вряд ли будет разумным подходом.

Основные течения в современном российском неоязычестве. Итак, определившись с понятийным аппаратом и терминологией, охарактеризуем современное состояние неоязычества в нашей стране, сосредоточившись на так называемом славянском неоязычестве. Но прежде всего отметим, что спектр неоязыческих групп, действующих в России, отнюдь не ограничивается теми, кто реконструирует дохристианские верования славян. Палитра отечественных неоязыческих групп и движений очень разнообразна, и сегодня в российских городах можно встретить представителей едва ли не всех течений неоязычества, существующих в современном мире. Действительно, неоязычество на протяжении последних десятилетий переживает заметный подъем, который охватил практически весь западный мир. И несмотря на то, что неоязычникам в целом свойственна тяга к реконструкции доавраамических верований собственных народов, поиску корней собственной национальной идентичности, этот подъем не мог не затронуть и нашу страну, вылившись в создание разнообразных групп, воспроизводящих группы неоязычников запада.

Какие же это группы? Предположительно, в силу отсутствия сколько-нибудь достоверной статистики, мы можем считать наиболее многочисленными группы последователей кельтского и германо-скандинавского неоязычества. В числе первых самыми многочисленными, судя по приблизительным оценкам, являются последователи движения викка. Викка или викканство - новое религиозное движение, появившееся в пятидесятые годы XX века и распространенное в англо-американском культурном ареале. Вероучение виккан не представляет собой стройной и обязательной для всех адептов системы взглядов и может варьироваться от сообщества к сообществу. Но, тем не менее, мы можем говорить и о некотором единстве этого довольно размытого движения, так как в его вероучении и культовых практиках наличествует общее ядро, восходящее к идеям его основателя Дж. Гарднера. В самом кратком изложении его доктрину можно охарактеризовать как попытку синтеза элементов западного эзотеризма с собственными представлениями основателя о дохристианской религии западноевропейцев, будто бы сохранившейся, несмотря на преследования инквизиции, в сообществе посвященных «ведьм». Характерной особенностью викканства является важная роль женщин в этом движении, что напрямую вытекает из поклонения женскому божеству, занимающему центральное место в викканском пантеоне. Женщины-«ведьмы», как правило, возглавля- 
ют викканские «ковены» - общины адептов, среди которых также преобладают женщины. Отечественные виккане, как и их западные единомышленники, в большинстве не политизированы и придерживаются весьма либеральных взглядов в вопросах морали, охотно принимая в свои ряды представителей ЛГБТсообщества. В силу этого виккане стоят несколько особняком по отношению к другим течениям отечественного неоязычества. Особенно резко ценности виккан контрастируют с установками адептов славянского неоязычества, которые, как правило, являются носителями ультраконсервативных патриархальных взглядов и зачастую придерживаются крайне правых политических убеждений. В целом же, несмотря на относительно большую численность виккан по отношению к другим течениям западного неоязычества, их абсолютное количество в нашей стране крайне незначительно и едва ли превышает несколько тысяч практикующих адептов.

Разнообразные группы последователей германо-скандинавского неоязычества, присутствующие в нашей стране, насколько можно судить, охотнее следуют скандинавскому, а не германскому варианту этого неоязыческого течения. В отличие от своих западноевропейских единомышленников отечественные последователи в целом демонстрируют большую приверженность правым и ультраправым политическим взглядам. Так, в этой среде заметной популярностью пользуется фигура Варга Викернеса - рок-исполнителя и ультраправого активиста, отбывшего длительное тюремное заключение за убийство на почве политических разногласий. В то же время нам не следует, как это иногда встречается в литературе, априори считать всех отечественных неоязычников этого направления носителями ультраправых взглядов, и как следствие, людьми, потенциально опасными для общества. Это - довольно пестрое течение, в котором можно встретить как политических радикалов, так и вполне аполитичных людей, привлеченных исключительно эстетической составляющей движения или увлекающихся рунической магией. Характерной чертой этого сообщества, отличающей его от аналогичных западных групп, является и крайне незначительный процент людей, воспринимающих мифологию и богов гер- мано-скандинавского пантеона, так сказать, всерьез, стремящихся установить с богами мистический контакт или апеллирующих в общении с единомышленниками к личному религиозному опыту. Германо-скандинавское неоязычество в отечественном варианте - явление, скорее, «политическое» и эстетическое, с изрядной составляющей реконструкторского движения, нежели собственно религиозное. Абсолютная численность адептов этого неоязыческого течения, даже с учетом людей, проявляющих к нему интерес исключительно на «теоретическом» уровне и не поддерживающих связей ни с одной практикующей общиной, также крайне незначительна в масштабах нашей страны.

Наряду с перечисленными выше, в нашей стране представлены еще меньшие, иногда буквально микроскопические по своему составу группы неоязычников, придерживающихся самых разнообразных убеждений, вПлоть до реконструкции религии Древнего Египта. Характерной особенностью всех упомянутых нами течений является ярко выраженная в последние годы виртуализация, то есть перемещение активности на просторы интернета, в основном в социальные сети. Группы соответствующей тематики в наиболее популярных социальных сетях могут насчитывать в некоторых случаях десятки тысяч участников. Однако эти, на первый взгляд, внушительные цифры мало что говорят о действительной численности приверженцев. По многочисленным свидетельствам, для абсолютного большинства участников этих групп следование неоязыческим взглядам ограничивается общением в мессенджерах и социальных сетях, что не позволяет рассматривать таких людей как действительно идентифицирующих себя с конкретными религиозными течениями. Подобная идентификация, сколь бы минимальной она ни была, во всяком случае предполагает хотя бы спорадическое участие в совместных ритуальных практиках.

Наиболее многочисленными, что ожидаемо, являются последователи так называемого славянского неоязычества, то есть течения, стремящегося, по утверждениям самих неоязычников, реконструировать дохристианские верования русского и ближайших к нему народов - украинцев и белору- 
сов. Отметим, что, исходя из современных знаний о генезисе русского народа, подобная реконструкция заранее обречена на провал. Русский народ как общность формируется позже, в дохристианские времена мы имеем дело с разрозненными родоплеменными сообществами. Однако неоязычники, как правило, не принимают во внимание или прямо отвергают подобные аргументы [8]. Мы вновь вынуждены констатировать невозможность в настоящее время оценить хоть сколько-нибудь точно численность адептов. Отсутствие достоверной статистики отчасти объясняется нерешенностью вопроса о том, кого именно следует считать неоязычником. Помимо практикующих адептов, входящих в организованные сообщества и более-менее регулярно участвующих в жизни общины и коллективных религиозных ритуалах, есть множество неоязычников-индивидуалистов, не принадлежащих ни к каким общинам, и довольно значительное количество людей, разделяющих эти убеждения, но не практикующих ни индивидуальных, ни коллективных ритуалов. Последние чаще всего выступают в качестве потребителей соответствующей сувенирной продукции, в больших количествах изготавливаемой как самими общинами, так и частными производителями, преследующими исключительно коммерческие интересы, посещают ежегодные фестивали и праздники, организуемые неоязыческими сообществами, поддерживают контакты с единомышленниками в социальных сетях.

Современное российское так называемое славянское неоязычество чрезвычайно пестро как по своему организационному составу, так и по своим идеологическим взглядам. Для построения классификации групп отечественного славянского неоязычества мы предлагаем обратиться к групповой самоидентификации различных ветвей этого движения [9]. Действительно, к настоящему времени внутри этого движения уже довольно четко просматриваются групповые идентичности: адепты различных ветвей проводят границы между своими единомышленниками и «чужаками», причем эти границы закрепляются в том числе и публичными декларациями. При этом «чужаки», как правило, определяются в качестве «ложных» неоязычников, не имеющих якобы никакого отношения к не- оязычеству «подлинному». Но здесь мы полностью согласимся с В.А. Мартиновичем: в науке отсутствуют какие-либо критерии, позволяющие разграничить «подлинное» и «неподлинное» неоязычество [10].

Итак, что же представляют собой эти течения? В настоящее время наиболее крупными из них являются группы, идентифицирующие себя в качестве «родноверов» и «староверов». Есть и более мелкие течения, опирающиеся на иную самоидентификацию, однако они, как нам представляется, являются слишком малочисленными и разнообразными для того, чтобы их можно было объединить в какую-либо однородную группу.

«Родноверы» тоже, в свою очередь, являются довольно неоднородным течением (правда, в настоящее время внутри этого направления заметны интегративные тенденции). Общим для них является стремление к «чистой» реконструкции славянского язычества с использованием сохранившихся источников, во-первых, и с опорой на личную религиозную интуицию, во-вторых. «Родноверы», как правило, отрицательно воспринимают как тенденции к религиозному синкретизму, так и попытки выстроить мифологию и вероучение, исходя исключительно из собственных, неверифицируемых представлений о славянской мифологии (что не мешает им, как мы сказали, также прибегать к религиозному творчеству). «Родноверы» являются, пожалуй, наиболее известным и узнаваемым течением внутри славянского неоязычества, так что зачастую в общественном мнении и в средствах массовой информации происходит отождествление родноверия со всем неоязыческим движением вообще. Несмотря на наличие внутри этой группы отдельных индивидуумов и небольших сообществ, разделяющих радикально националистические взгляды, в последние годы явно выражена тенденция крупных родноверческих объединений к приобретению положительного имиджа в глазах общественности и к легализации своего статуса в качестве законопослушных зарегистрированных религиозных объединений.

Движение, использующее в качестве самоназвания термин «староверы», возникло около тридцати лет назад благодаря деятельности А.Ю. Хиневича, жителя Омска (риту- 
альное имя - Патер Дий Александр). Другие самоназвания, используемые в этом течении, - «православные», «православные староверы», «православные староверы-инглинги», «инглинги», «ингляне» и т.п. (по трактовке самих «староверов», самоназвание «православные» якобы исконно принадлежало язычникам и образовано от выражения «славить Правь», а затем было «похищено» христианами). «Староверы» вполне последовательно отличают себя от «родноверов», и наоборот. Для «староверов» - последователей инглиизма характерен религиозный синкретизм и безудержное мифотворчество, а также приверженность «альтернативной истории» и лженаучным идеям в целом [11]. Этому движению также присущи резкая антихристианская направленность и ярко выраженный расизм, что неоднократно приводило «староверов» к конфликтам с законом. Так, созданная А. Ю. Хиневичем религиозная организация «Древнерусская инглиистическая церковь православных староверов-инглингов» была запрещена, а сам основатель подвергался уголовному преследованию. Также попало под запрет и основное вероучительное сочинение этой организации - «Славяно-арийские веды». Тем не менее, религиозные группы, имеющие организационную и вероисповедную связь с запрещенной «церковью», действуют в нашей стране и в настоящее время $[12,13]$.

Особо важно отметить, что влияние идеологии «староверов» не ограничивается собственно кругом адептов. «Староверы» весьма активны в интернете - созданные ими группы и паблики в социальных сетях могут насчитывать десятки тысяч подписчиков, что в несколько раз превосходит количество участников официальных групп всех наиболее крупных объединений «родноверов», вместе взятых. С идеологией «староверов» также тесно связаны взгляды ряда популярных в неоязыческом движении лиц, также высказывавших радикальные взгляды, и сочинения которых также были запрещены как экстремистские - например, А.В. Трехлебова (ритуальное имя Ведаман Ведагор), Н.В. Левашова. Кроме того, популяризации идеологии староверов со всеми ее, мягко выражаясь, проблемными элементами способствует достаточно широкая акцепта- ция элементов их идеологии различными группами, относящимися к движению «нью эйдж». Таким образом, можно заключить, что движение «староверов» к настоящему времени приобрело значительную популярность и представляет собой, по меньшей мере, социально проблемное явление.

Заключение. Таким образом, мы можем прийти к выводу: современное отечественное неоязычество представляет собой чрезвычайно пестрое по своим вероучениям и идеологическим установкам явление, что существенно затрудняет его анализ, типологизацию, выработку релевантного понятийного аппарата и терминологии. Среди отечественных неоязыческих групп присутствуют придерживающиеся радикальных взглядов, что создает вызовы общественной безопасности [14], но, тем не менее, нет никаких оснований рассматривать в качестве потенциально проблемных все без исключения направления отечественного неоязычества. Это обстоятельство вызывает необходимость дальнейшего тщательного исследования неоязыческих групп: было бы одинаково недопустимо как проглядеть тревожные тенденции и позволить им укрепиться в неоязыческой среде, так и подвергнуть необоснованному давлению социально непроблемные группы, члены которых являются законопослушными гражданами, реализующими свое конституционное право на свободу совести.

\section{Литература}

1. Aстапов C. Н. Антропология неоязычников-родноверов // Человек и религия: материалы Междунар. науч.-практ. конф., 1416 марта 2013 г., Минск, Республика Беларусь / Под ред. С. Г. Карасевой, С.И. Шатравского. - Минск, 2013. - С. 456-463.

2. Шнирельман В.А. Русское родноверие: неоязычество и национализм в современной России. - М.: Изд-во ББИ, 2012. - 195 с.

3. Эгильский Е. Э., Касьянов В.В., Самыгин С.И. Современное славянское неоязычество: сущность, предпосылки, перспективы [Электронный ресурс] // Национальное здоровье / National Health. - №2. - 2018. Режим доступа: http://www.national-zdorov.ru/ 
userfiles/file/ntjykoh2uwbxngrscyeq3w8p3kuw oqym.pdf (Дата обращения: 30.11.2020).

4. Kasyanov V.V., Belikova N.Y., Krotov D. V., Samygin S.I., Merzakanov S.A. Religious orientations of modern youth and the national policy // Advances in Intelligent Systems and Computing. - 2020. - Vol. 1100 AISC. P. 601-613.

5. Белов М. Т., Гафиатулина Н.Х., Самьгин С.И. Управление религиозными ориентирами в сознании современной молодежи // Экономические проблемы России и региона. Ученые записки. Ростовский государственный экономический университет (РИНХ). Ростов-на-Дону, 2019. - С. 186-193.

6. Шнирельман В. А. Перун, Сварог и другие: русское неоязычество в поисках себя // Неоязычество на просторах Евразии: Сборник / Под. ред. В.А. Шнирельмана. - М.: Библейско-Богословский институт св. апостола Андрея, 2001. - 177 с.

7. Кузнецов М.Н. Российское неоязычество. История, идеи и мифы. - Рязань: ЗернаСлово, 2018. - $176 \mathrm{c.}$

8. Клейн Л.С. Воскрешение Перуна. К реконструкции восточнославянского язычества. - СПб.: Евразия, 2004. - 480 с.

9. Кавыкин О.И. «Родноверы». Самоидентификация неоязычников в современной России [Электронный ресурс]. — Режим доступа: https://stavroskrest.ru/sites/default/files/ files/books/kavikin_pdf (Дата обращения: 30.11.2020).

10. Мартинович В. A. Проблематика целостного восприятия феномена неоязычества // Язычество в современной России: опыт междисциплинарного исследования. Монография / Под ред. Р.В. Шиженского. - Н. Новгород: Мининский Университет, ООО «Типография "Поволжье"», 2016. - C. 167-168.

11. Эгильский Е. Э. Мифология истории в вероучениях новых религиозных движений [Электронный ресурс] // Актуальные проблемы науки и техники. 2017. Материалы нац. науч.-практ. конф. Ростов-на-Дону, 15-17 мая 2017 г. Донской гос. техн. ун-т. - Ростов-наДону: ДГТУ, 2017. - 388 с. - Режим доступа: https://ntb.donstu.ru/conference (Дата обращения: 30.11.2020).

12. Эгильский Е. Э., Касьянов В.В., Самыгин С.И. Современное неоязычество и «альтернативная наука» // Национальное здоровье. - 2018. - №3. - С. 178-182.

13. Гафиатулина Н.Х., Касьянов В.В., Самылин П.С., Самызин С.И. Российское общество в условиях самоизоляции. Социальные эффекты и последствия пандемии Covid-19. Монография. - Москва, 2020.

14. Шнирельман B.A. Неоязычество и национализм (восточноевропейский ареал) [Электронный ресурс]. - Режим доступа: http://static.iea.ras.ru/neotlozhka/114-Shnirelman. pdf (Дата обращения: 30.11.2020).

\section{References}

1. Astapov S.N. Antropologija neojazychnikov-rodnoverov [Anthropology of the neopagans-rodnovers] // Chelovek i religija: materialy Mezhdunar. nauch.-prakt. konf., 14-16 marta 2013 g. [Man and Religion: materials of the International Scientific and Practical Conference, 14-16 March 2013], Minsk, Respublika Belarus'/ In S. G. Karaseva, S. I. Shatravskiy (eds.). - Minsk, 2013. - Pp. 456-463.

2. Shnirel'man V.A. Russkoe rodnoverie: neojazychestvo i nacionalizm $\mathrm{v}$ sovremennoj Rossii [Russian rodnoverie: neo-paganism and nationalism in modern Russia]. - Moscow: Izdvo BBI, 2012. - $195 \mathrm{p}$.

3. Jegil'skij E. Je., Kas'janov V. V., Samygin S.I. Sovremennoe slavjanskoe neojazychestvo: sushhnost', predposylki, perspektivy [Modern Slavic neo-paganism: essence, prerequisites, prospects] [Jelektronnyj resurs] // Nacional'noe zdorov'e / National Health. №2. - 2018. - URL: http://www.national-zdorov.ru/userfiles/file/ntjykoh2uwbxngrscyeq3w8p3kuwoqym.pdf (Date accessed: 30.11.2020).

4. Kasyanov V.V., Belikova N.Y., Krotov D. V., Samygin S. I., Merzakanov S.A. Religious orientations of modern youth and the national policy // Advances in Intelligent Systems and Computing. - 2020. - Vol. 1100 AISC. P. 601-613.

5. Belov M.T., Gafiatulina N.H., Samygin S.I. Upravlenie religioznymi orientirami $\mathrm{v}$ soznanii sovremennoj molodezhi [Management of religious landmarks in the consciousness of modern youth] // Jekonomicheskie problemy Rossii i regiona. Uchenye zapiski. Rostovskij gosudarstvennyj jekonomicheskij universitet 
(RINH) [Economic problems of Russia and the region. Scientific notes. Rostov State University of Economics (RSUE)]. - Rostov-on-Don, 2019. - Pp. 186-193.

6. Shnirel'man V.A. Perun, Svarog i drugie: russkoe neojazychestvo v poiskah sebja [Perun, Svarog and others: Russian neo-paganism in search of itself] // Neojazychestvo na prostorah Evrazii: Sbornik [Neo-paganism in the expanses of Eurasia: A collection] / In V.A. Shnirel'man (eds.). - Moscow: Biblejsko-Bogoslovskij institut sv. apostola Andreja, 2001. - 177 p.

7. Kuznecov M.N. Rossijskoe neojazychestvo. Istorija, idei i mify [Russian neo-paganism. History, ideas and myths]. - Rjazan: Zerna-Slovo, 2018. - $176 \mathrm{p}$.

8. Klejn L.S. Voskreshenie Peruna. K rekonstrukcii vostochnoslavjanskogo jazychestva [The Resurrection of Perun. Towards the reconstruction of East Slavic paganism]. - Saint-Petersburg: Evrazija, 2004. - 480 p.

9. Kavykin O.I. «Rodnovery». Samoidentifikacija neojazychnikov v sovremennoj Rossii [Self-identification of neo-pagans in modern Russia] [Jelektronnyj resurs]. — URL: https:// stavroskrest.ru/sites/default/files/files/books/kavikin_pdf (Date accessed: 30.11.2020).

10. Martinovich V.A. Problematika celostnogo vosprijatija fenomena neojazychestva [Problematics of holistic perception of the phenomenon of neo-paganism] // Jazychestvo v sovremennoj Rossii: opyt mezhdisciplinarnogo issledovanija. Monografija [Paganism in Modern Russia: experience in interdisciplinary research. Monograph] / In R. V. Shizhenskiy (eds.). - N. Novgorod: Mininskij Universitet,
OOO «Tipografija "Povolzh'e"», 2016. Pp. 167-168.

11. Jegil'skij E. Je. Mifologija istorii v verouchenijah novyh religioznyh dvizhenij [The history of Mythology in the beliefs of new religious movements] [Jelektronnyj resurs] // Aktual'nye problemy nauki i tehniki. 2017. Materialy nac. nauch.-prakt. konf. Rostov-na-Donu, 15-17 maja 2017 g. Donskoj gos. tehn. un-t [Actual problems of science and technology. 2017. Materials of the National Scientific and practical Conference. Rostov-on-Don, May 15-17, 2017 Don State Technical University]. - Rostovon-Don: DGTU, 2017. — 388 p. — URL: https://ntb.donstu.ru/conference (Date accessed: 30.11.2020).

12.Jegil'skijE.Je., Kas'janovV.V., Samygin S.I. Sovremennoe neojazychestvo i «al'ternativnaja nauka» [Modern neo-paganism and «alternative science»] // Nacional'noe zdorov'e [National Health]. — 2018. — №3. — Pp. 178-182.

13. Gafiatulina N.H., Kas'janov V. V., Samygin P.S., Samygin S.I. Rossijskoe obshhestvo v uslovijah samoizoljacii. Social'nye jeffekty i posledstvija pandemii Covid-19. Monografija [Russian society in the conditions of self-isolation. Social effects and consequences of the Covid-19 pandemic. Monograph]. - Moscow, 2020.

14. Shnirel'man V.A. Neojazychestvo i nacionalizm (vostochnoevropejskij areal) [Neopaganism and nationalism (Eastern European area)] [Jelektronnyj resurs]. — URL: http:// static.iea.ras.ru/neotlozhka/114-Shnirelman.pdf (Date accessed: 30.11.2020). 


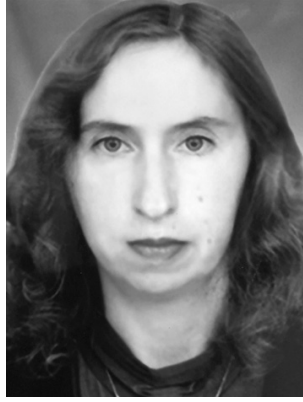

Левандина Ирина Александровна - кандидат философских наук, доцент кафедры гуманитарных и социально-экономических дисциплин Ростовского юридического института МВД России. Специалист в области статистики, менеджмента, экономической теории, профессиональной этики и служебного этикета, проблем отчуждения и идентичности человека, миграционных процессов, духовно-нравственных проблем современной молодежи. Стаж научно-педагогической работы - 9 лет.

Levandina Irina Alexandrovna - Candidate of Philosophical Sciences, Associate Professor, Department of Humanities and Socio-economic Sciences, Rostov Law Institute of the Ministry of Internal Affairs of Russia. Specialist in statistics, management, economic theory, professional ethics and official etiquette, problems of alienation and human identity, migration processes, spiritual and moral problems of modern youth. The experience of scientific and pedagogical work is 9 years.

344015, г. Ростов-на-Дону, ул. Еременко, 83

83 Eremenko st., 344015, Rostov-on-Don, Russia

E-mail: levandina@rgkiu.ru

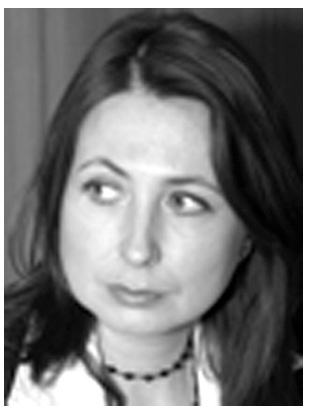

Липчанская Ирина Владимировна - кандидат философских наук, доцент кафедры философии и культурологии Ростовского государственного экономического университета (РИНХ). Сфера научных интересов: элитология, проблемы генезиса научной элиты, исследования в сфере философии и методологии науки. Стаж научной работы - 18 лет.

Lipchanskaya Irina Vladimirovna - Candidate of Philological Sciences, Associate Professor of Philosophy and Cultural Studies of Rostov State University of Economics (RSUE). Research interests: elitology, the genesis of the scientific elite, research in the field of philosophy and methodology of science. Experience of scientific work - 18 years.

344002, г. Ростов-на-Дону, ул. Большая Садовая, 69

69 Bolshaya Sadovaya st., 344002, Rostov-on-Don, Russia

E-mail: lipiv@list.ru. 


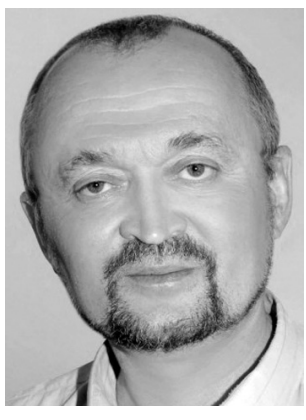

Самыгин Сергей Иванович - профессор, доктор социологических наук, профессор кафедры управления персоналом и социологии Ростовского государственного экономического университета (РИНХ).

Samygin Sergey Ivanovich - Professor, Doctor of Sociological Sciences, Professor, Department of Personnel Management and Sociology, Rostov State University of Economics (RSUE).

344002, г. Ростов-на-Дону, ул. Большая Садовая, 69

69 Bolshaya Sadovaya st., 344002, Rostov-on-Don, Russia

E-mail: darya.maksimovich@gmail.com 